\title{
Sestrin2: Its Potential Role and Regulatory Mechanism in Host Immune Response in Diseases
}

\author{
$\mathrm{Li}_{\text {-Xue Wang }}{ }^{1 \dagger}$, Xiao-Mei Zhu ${ }^{1 \dagger}$ and Yong-Ming Yao ${ }^{1,2 *}$ \\ ${ }^{1}$ Trauma Research Center, Fourth Medical Center of the Chinese PLA General Hospital, Beijing, China, ${ }^{2}$ State Key \\ Laboratory of Kidney Disease, The Chinese PLA General Hospital, Beijing, China
}

OPEN ACCESS

Edited by:

Haichao Wang,

Feinstein Institute for Medical

Research, United States

Reviewed by:

Nina Zeng,

The University of Auckland,

New Zealand

Luiz Eduardo Baggio Savio,

Federal University of Rio de

Janeiro, Brazil

*Correspondence:

Yong-Ming Yao

c_ff@sina.com

tThese authors have contributed equally to this work

Specialty section: This article was submitted to Inflammation,

a section of the journal

Frontiers in Immunology

Received: 18 September 2019 Accepted: 14 November 2019

Published: 04 December 2019

Citation:

Wang LX, Zhu XM and Yao YM (2019) Sestrin2: Its Potential Role and Regulatory Mechanism in Host Immune Response in Diseases.

Front. Immunol. 10:2797.

doi: 10.3389/fimmu.2019.02797
Sestrin2 (SESN2), a highly evolutionarily conserved protein, is critically involved in cellular responses to various stresses. SESN2 has a protective effect on physiological and pathological states mainly via regulating oxidative stress, endoplasmic reticulum stress, autophagy, metabolism, and inflammation. In recent years, breakthrough investigations with regard to the regulation and signaling mechanisms of SESN2 have markedly deepened our understanding of its potential role as well as its significance in host response. However, the functions of SESN2 in the immune system and inflammation remain elusive. It has been documented that many immune cells positively express SESN2 and, in turn, that SESN2 might modulate cellular activities. This review incorporates recent progress and aims to provide novel insight into the protective role and regulatory pathway of SESN2, which acts as a potential biomarker and therapeutic target in the context of various diseases.

Keywords: Sestrin2, immune response, autophagy, endoplasmic reticulum stress, immune cell

\section{INTRODUCTION AND BACKGROUND}

Sestrins (SESNs), a highly evolutionarily conserved protein family, can be induced by various stresses, including oxidative stress, DNA damage, hypoxia, and nutritional stress (1-5). The SESN proteins play important roles in protecting organisms and cellular homeostasis from stress injury mainly by downregulation of reactive oxygen species (ROS) accumulation and the mammalian target of rapamycin protein kinase (mTOR) signaling (5-9). Increasing numbers of studies have documented that three SESN genes, SESN1 (PA26), SESN2 (Hi95), and SESN3, have been identified in most vertebrates, while only one SESN gene has been found in invertebrates, and no SESN genes have been found in yeast (6). The first gene of this family, named SESN1 (PA26), was initially discovered in 1999 as a p53 transcription factor in the cellular response to genotoxic stress from treatment with ultraviolet (UV), $\gamma$-irradiation, and cytotoxic drugs in 1999 (2). Several years later, SESN2, which is highly homologous to the SESN1 gene, was identified under hypoxic conditions, while p53 was dispensable to this process (3). SESN3 was observed as a gene that was activated by the forkhead transcription factor (FoxO) under conditions of energy crisis $(9,10)$. Although these proteins share high similarity of biological structure with each other and show some common effects in modulation of 5 '-adenosine monophosphate-activated protein kinase (AMPK) and mTOR, there are also many differences. Additionally, they lack an obvious structural effector domain, and no clear function has been found during the years.

Growing evidence has demonstrated that the three members of the SESNs perform diverse functions (Table 1). SESN1 is associated with autophagy-related genes and can inhibit mTORC1 
TABLE 1 | Identified functions of three member of the SESN family.

\begin{tabular}{|c|c|c|c|c|c|}
\hline System diseases & SESNs & Type of disease & Effect & Mechanisms & References \\
\hline \multirow[t]{2}{*}{$\begin{array}{l}\text { Immune } \\
\text { system }\end{array}$} & $\begin{array}{l}\text { SESN1, } \\
\text { SESN2, } \\
\text { SESN3 }\end{array}$ & T-cell senescence & Pro-aging function in T lymphocytes & Activating Erk-JNK-p38 MAPK complex & (11) \\
\hline & SESN2 & Sepsis and sepsis shock & Protect the host from sepsis & $\begin{array}{l}\text { Inducing mitophagy and inhibiting } \\
\text { prolonged inflammasome activation }\end{array}$ & $(12)$ \\
\hline \multirow[t]{2}{*}{ Liver disease } & SESN2 & Liver damage, hepatosteatosis & Hepatoprotective effect & $\begin{array}{l}\text { Inhibiting oxidative stress response and } \\
\text { prolonged ER stress }\end{array}$ & $(13-18)$ \\
\hline & SESN3 & Nonalcoholic steatohepatitis & $\begin{array}{l}\text { Protect against diet-induced } \\
\text { non-alcoholic steatohepatitis }\end{array}$ & Suppressing of TGF- $\beta$-Smad3 signaling & (19) \\
\hline $\begin{array}{l}\text { Ischemia- } \\
\text { reperfusion (I/R) } \\
\text { injury }\end{array}$ & SESN2 & $\begin{array}{l}\text { Cardiovascular/ renal/cerebral I/R } \\
\text { injury }\end{array}$ & $\begin{array}{l}\text { Protective capabilities against I/R } \\
\text { injury }\end{array}$ & $\begin{array}{l}\text { Promoting AMPK activation or activating } \\
\text { autophagy and mitophagy }\end{array}$ & $(20-25)$ \\
\hline \multirow[t]{2}{*}{$\begin{array}{l}\text { Neurodegenerative } \\
\text { disease }\end{array}$} & SESN2 & $\begin{array}{l}\text { Neuropathic pain, Alzheimer's } \\
\text { disease, Parkinson's disease, } \\
\text { Huntington' disease }\end{array}$ & Neuroprotection & $\begin{array}{l}\text { Antioxidant against ROS, activating } \\
\text { AMPK-dependent autophagy and } \\
\text { suppressing mTORC1 }\end{array}$ & $(26-29)$ \\
\hline & SESN3 & Temporal lobe epilepsy & $\begin{array}{l}\text { Modulating brain inflammation and } \\
\text { epilepsy }\end{array}$ & Regulating pro-convulsant gene network & $(30)$ \\
\hline \multirow[t]{2}{*}{$\begin{array}{l}\text { Cardiovascular } \\
\text { disease }\end{array}$} & SESN1 & Cardiac hypertrophy & Anti-hypertrophic function & $\begin{array}{l}\text { Activating autophagy via regulating } \\
\text { AMPK/mTORC1 }\end{array}$ & (31) \\
\hline & SESN2 & $\begin{array}{l}\text { Cardiac hypertrophy, myocardial } \\
\text { infarct, ischemic cardiomyopathy } \\
\text { and dilated cardiomyopathy, } \\
\text { atherosclerosis }\end{array}$ & $\begin{array}{l}\text { Protective effect on cardiovascular } \\
\text { remodeling and regeneration }\end{array}$ & $\begin{array}{l}\text { Inhibiting ERK1/2 signaling, enhancing } \\
\text { antioxidant effect on the Nrf2/Keap1 } \\
\text { pathway }\end{array}$ & $(32-35)$ \\
\hline Lung disease & SESN2 & COPD, emphysema & Negative effect on pulmonary function & $\begin{array}{l}\text { Regulating the TGF- } \beta \text { and mTOR } \\
\text { pathways }\end{array}$ & $(36,37)$ \\
\hline \multirow[t]{3}{*}{ Cancer } & SESN1 & Thyroid cancer, follicular lymphoma & Tumor inhibitory effect & $\begin{array}{l}\text { Regulating the p53-AMPK-mTOR } \\
\text { signaling pathway }\end{array}$ & $(38,39)$ \\
\hline & SESN2 & $\begin{array}{l}\text { Most cancers in diverse organ } \\
\text { systems }\end{array}$ & Tumor inhibitory effect & $\begin{array}{l}\text { Activating MAPK8/JNK1, inhibiting the } \\
\text { mTORC1 pathway }\end{array}$ & $(40-44)$ \\
\hline & SESN3 & $\begin{array}{l}\text { Chronic myeloid leukemia, } \\
\text { lung cancer }\end{array}$ & $\begin{array}{l}\text { Anti-leukemic responses, tumor } \\
\text { inhibitory effect }\end{array}$ & Inhibiting the PI3K/AKT/mTOR pathway & $(45,46)$ \\
\hline \multirow[t]{2}{*}{ Aging } & SESN1 & $\begin{array}{l}\text { Delay aging and age-associated } \\
\text { disorders }\end{array}$ & Regulating life span & Suppression of ROS accumulation & $(47)$ \\
\hline & $\begin{array}{l}\text { SESN2 } \\
\text { SESN3 }\end{array}$ & Insulin resistance & $\begin{array}{l}\text { Control of lipid and glucose } \\
\text { metabolism and liver insulin resistance }\end{array}$ & Inhibiting mTORC1-S6K signaling & $(48)$ \\
\hline
\end{tabular}

or ROS in cells (5). SESN2 has an antioxidant function, activates AMPK, and inhibits mTORC1 signaling $(5,6)$. SESN3 suppresses mTORC1 activity and maintains Akt activity by activating the AMPK/TSC1/2 axis $(10,49)$. Among these members, SESN2 has been the most profoundly investigated since its discovery in 2002;

\footnotetext{
Abbreviations: mTOR, mammalian target of rapamycin; ROS, reactive oxygen species; FoxO, forkhead box transcription factor belonging to the O-subclass; AMPK, AMP-activated protein kinase; TSC, tuberous sclerosis complex protein; Nrf2, NF-E2-related factor 2; AP-1, activator protein 1; Ucp1, uncoupling protein 1; Keap1, Kelch-like ECH-associated protein 1; VEGF, vascular endothelial growth factor; PI3K/Akt, phosphoinositide-3 kinase/Akt; PAMP, pathogen-associated molecular patterns; ULK1, Unc-51-like protein kinase 1; UPR, unfolded protein response; PERK, PER-like endoplasmic reticulum kinase; eIF2 $\alpha$, eukaryotic translation initiation factor $2 \alpha$; IRE1, inositol-requiring enzyme 1; XBP1, Xbox binding protein 1; ATF6, activating transcription factor 6; ATF4, activating transcription factor 4; JNK, c-Jun N-terminal kinase; sMAC, sestrin-MAPK activation immune-inhibition complex; NLRP3, NLR family, pyrin domain containing 3; I/R, ischemia-reperfusion; PGC- $1 \alpha$, peroxisome proliferatoractivated receptor gamma coactivator-1; MCAO, permanent middle cerebral artery occlusion; HAND, human immunodeficiency virus (HIV)-associated neurocognitive disorders; COPD, chronic obstructive pulmonary disease.
}

investigations concerning the structure or function of SESN1 and SESN3 have been limited. Previous studies have revealed that the structure of human SESN2 (hSESN2) displays three subdomains, namely, SESN-A, SESN-B, and SESN-C (50-52). The domain of SESN-A functions as an active alkyl hydroperoxide reductase, which is critical for parts of its antioxidant effect. The site of SESN-B, a leucine-binding site, illuminates the way that SESN2 interacts with leucine. SESN-C interacts with GTPase-activating protein complex for Rag (GATOR2) and performs a pivotal role in the regulation of AMPK and mTORC1 signaling by hSESN2. Current research on the SESN family is shown in Figure 1.

SESN2 was initially observed as a downstream effector of p53, and a myriad of adverse environmental stresses can induce SESN2 expression, such as oxidative stress, endoplasmic reticulum (ER) stress (ERS), energetic stress, and age- and obesity-associated metabolic pathologies $(9,53-58)$. It has been reported that SESN2 has pleiotropic biologic functions in cell homeostasis and metabolic homeostasis during diverse conditions by regulating autophagy, ERS, and inflammasome activity. However, the effect of SESN2 on the inflammatory 


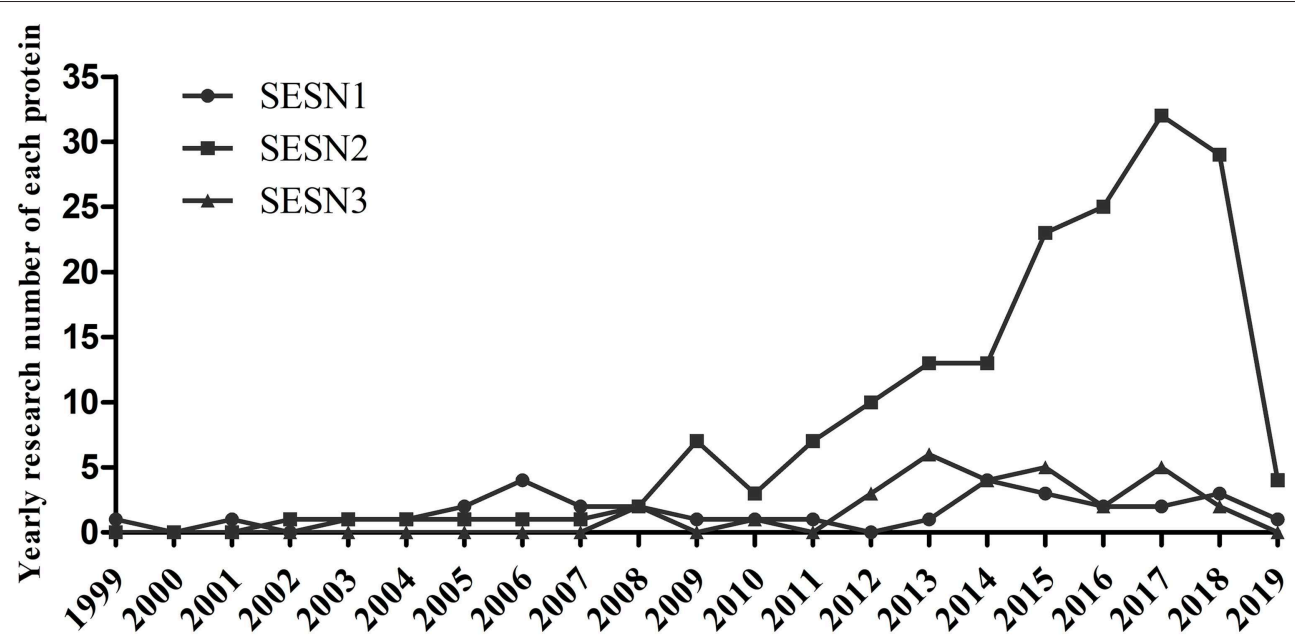

FIGURE 1 | Current research situation of the SESN family. PubMed search in May 2019.

and immune systems is still not yet well understood. The current review focuses on functions, pathophysiological effects, and regulatory mechanisms of SESN2 in the development of inflammatory-related diseases (Figure 2).

\section{REGULATION OF SESN2 INDUCTION}

As a stress-induced protein, SESN2 can be regulated to adapt to various metabolic stimuli at the cellular or organism level. Thus, it is pivotal to investigate how SESN2 expression is regulated during diverse physiological and pathological conditions.

\section{DNA Damage}

DNA damage can be provoked by different stresses, and it might result in metabolic homeostasis and tissue inflammation. p53 plays a key role in the regulation of cellular responses to DNA damage, and it is involved in the modulation of cell cycle arrest, cellular apoptosis, and metabolic dysfunction (59). It was reported that SESN2 was upregulated in a p53dependent manner in response to DNA damage and played an important role in maintaining cellular activity $(3,5)$. In accordance with previous studies in fibroblasts and keratinocytes, Mlitz et al. (60) found that ultraviolet-B (UVB) irradiation obviously induced DNA damage, which increased the SESN2 level, and this upregulatory response could be abolished by silencing p53. Moreover, the p53 and Akt pathways are vital for UVB irradiation-mediated SESN2 upregulation in melanocytes (61). In sebaceous gland carcinoma, p53 appeared to be required for SESN2 induction, and a low level of SESN2 was related to advanced tumor stage and poor prognosis (62).

\section{Oxidative Stress}

Oxidative stress occurs when ROS are excessively produced and antioxidant systems are unable to balance the response, which can trigger various inflammatory mediators in inflammationassociated chronic diseases (63). Nuclear factor erythroid 2related factor $2(\mathrm{Nrf} 2)$ acts as a crucial transcription factor that can modulate antioxidant gene expression by interacting with the antioxidant response elements (AREs). Under physiological conditions, Nrf2 binds to its negative repressor Kelch-like ECHassociated protein 1 (Keap1) and is inactivated (64). SESN2, with antioxidant property, is transcriptionally induced by oxidative stress, and its upregulation is vital in attenuating oxidative damage and maintaining cellular viability and cellular functions $(13,53,65-67)$.

For instance, in hepatocytes, Shin et al. (53) demonstrated that Nrf2 activators specifically upregulated the expression of SESN2 but not SESN1 and SESN3 in a time- and dose-dependent manner and that Nrf2-ARE pathway activation seemed to be essential for SESN2 induction. In turn, SESN2 might act as a positive modulator of Nrf2 signaling, which shows a beneficial effect in Nrf2-mediated oxidative stress. Interestingly, it has been reported that SESN2 is closely related to both Keap1 and the autophagy adapter p62/sequestosome-1 (65). Bae et al. (65) revealed that SESN2 protected against oxidative damage by enhancing Keap1 degradation mechanistically via p62-mediated autophagic degradation and consequent Nrf2 activation. More recently, in brown adipose tissue (BAT) metabolism, SESN2 played an antioxidant defense role in mitochondrial and BAT metabolism by inhibiting Ucp1 expression associated with ROS-mediated p38 mitogen-activated protein kinase (MAPK) activation $(66,68)$. In summary, these data suggest that oxidative stress can induce SESN2 expression and that SESN2 acts as a defense regulator against excessive oxidative stress to protect cells through various transcription pathways.

\section{Hypoxia}

Hypoxia, one of the most severe metabolic insults, has lower oxygen content and pressure in cells and can lead to pathological tissue damage or inflammation. SESN2 was originally identified as a novel gene under hypoxic conditions in a p53-independent and hypoxia-induced factor- $1 \alpha$ (HIF-1 $\alpha$ )-independent manner in various cells both in vivo and in vitro (3), which appears to be in 


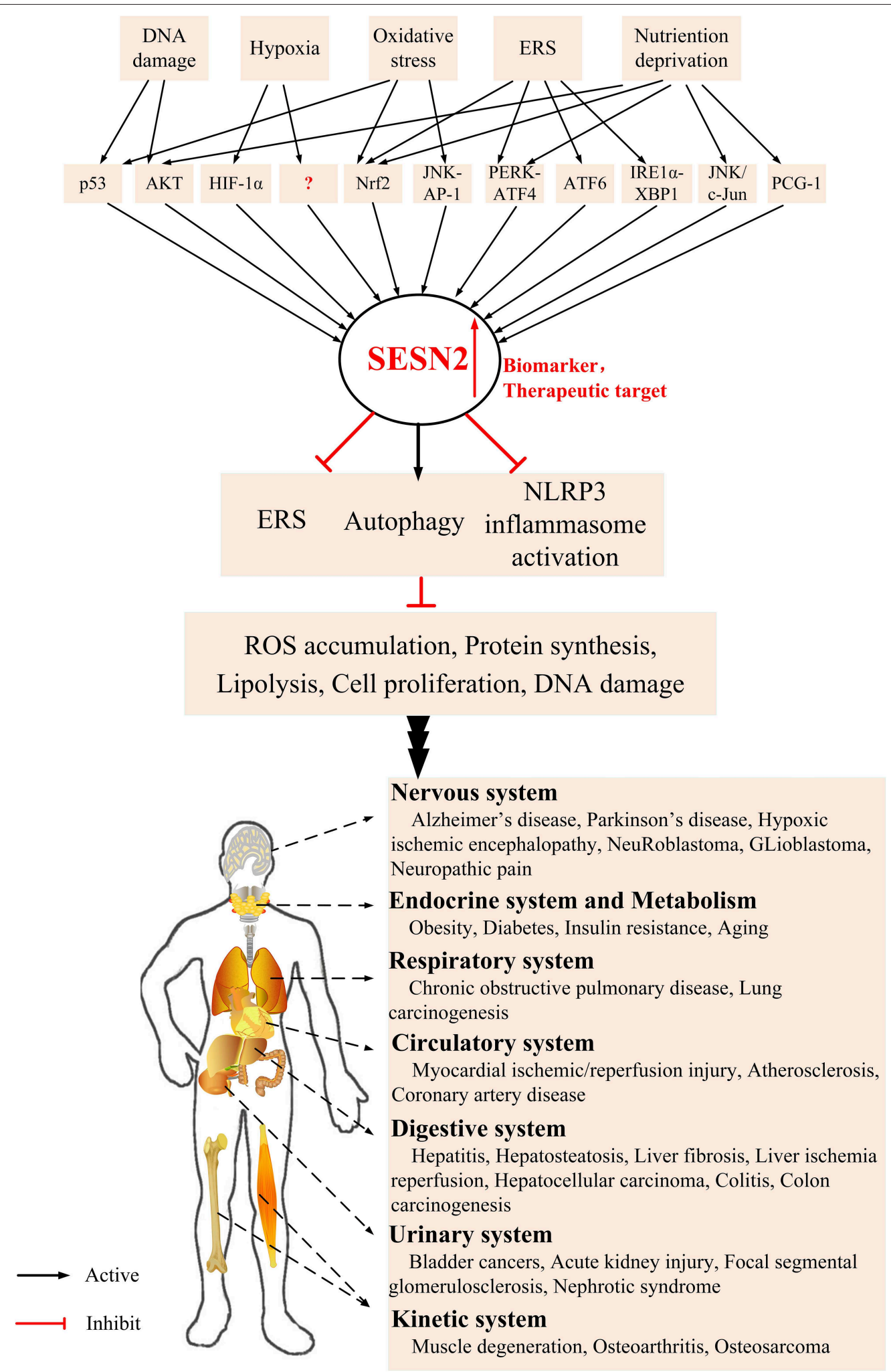

FIGURE 2 | The underlying mechanism of SESN2 induction and potential role of SESN2 as a therapeutic target in diverse systems. Various stress insults increase the expression of SESN2 via regulation of several critical transcription factors. Upregulation of SESN2 inhibits ROS accumulation, protein synthesis, lipogenesis, cell proliferation, and DNA damage through alleviating the extent of ERS, activating autophagy, or relieving inflammasome activation. SESN2, with several modulatory effects, acts as an advantageous therapeutic target and provides protective roles in various inflammatory disorders. 
contrast to other studies in which the induction of SESN2 is HIF$1 \alpha$ dependent (69-71). Essler et al. (70) found that hypoxia and nitric oxide (NO) strongly induced SESN2 expression in a HIF$1 \alpha$-dependent manner in RAW264.7 cells and that the activation of SESN2 prevented peroxiredoxin overoxidation to protect cells. In addition, in hypoxia-ischemic encephalopathy models, severe hypoxia-ischemic injury upregulated SESN2 expression in a HIF$1 \alpha$-dependent manner, and SESN2 inhibited vascular endothelial growth factor formation and attenuated brain infarction or edema (71).

SESN2 could suppress HIF-1 $\alpha$ accumulation and hypoxia response element (HRE)-dependent gene transcription by regulating AMPK-prolyl hydroxylase (PHD) in colorectal cancer cells, showing its antitumor effect (72). A recent study reported that the upregulation of SESN2 not only by hypoxia itself but also by prolonged hypoxia caused energy stress by diverse modulators (56). Thus, hypoxia can induce the expression of SESN2, while the precise mechanisms under hypoxia remain unclear and need further studies.

\section{Nutrient Starvation}

AMPK and mTORC1 are crucial nutrient sensors that modulate metabolic energy homeostasis at the whole-body level. When responding to stresses, SESN2 exerts a protective effect by activating AMPK and inhibiting mTORC1 signaling $(5,6)$. It has been documented that SESN2 is the only SESN family member that is increased under energy deficiency and that the phosphoinositide-3 kinase/Akt (PI3K/Akt) pathway, but not $\mathrm{p} 53$, is required for SESN2 induction (56). Meanwhile, SESN2 markedly protected against energy deprivation-induced cell apoptosis via inhibiting the mTOR pathway (56). Glucose deprivation increased SESN2 expression, which was dependent on Nrf2-ARE activation in hepatocytes, which was related to glucose deprivation-induced ROS accumulation. Thus, SESN2 might play a pivotal role in the cellular adaptive response by increasing AMPK activity to maintain mitochondrial homeostasis (73). In agreement with this study, Ding et al. (54) reported that SESN2 was the major responder that was activated among SESN family members during energy stress, and its induction mechanism was dependent on ERS transcription factors including activating transcription factor (ATF) 4 and Nrf2 but not p53. Additionally, as is known, leucine, a proteogenic amino acid, facilitates mTORC1 by the Rag GTPases, as well as their regulators GATOR1 and GATOR2. SESN2 binds to GATOR2 in cells in an amino-acid-sensitive manner (8, 74, 75). Upon amino acid depletion, the expression of SESN2 was increased, and the structure was altered, which manifested as SESN2 becoming more highly phosphorylated and the SESN2-GATOR2 interaction being much effective, leading to a suppression of the mTORC1 signaling and then regulating protein synthesis as well as autophagy $(50,75)$.

In cancer cells, c-Jun N-terminal kinase (JNK) pathway activation and its downstream factor c-Jun phosphorylation are required for the regulation of SESN2 transcription under serum deprivation (76). In a recent study, SESN2 expression was found to depend on peroxisome proliferator-activated receptor-coactivator (PGC)-1 $\alpha$ activation under glucose scarcity in liver cancer cells (77).

\section{REGULATORY MECHANISMS OF SESN2}

In response to various stimuli, SESN2 is known to inhibit mTORC1 by activating AMPK signaling and prevent ROS accumulation in cells. Increasing evidence shows that different cell signaling pathways are regulated by SESN2, including autophagy, ERS, and inflammasomes, in response to stimuli to exert cytoprotective effects.

\section{Autophagy}

Autophagy, a self-degradation process, is a basic metabolic mechanism to maintain cellular homeostasis and survival by degrading intracellular proteins as well as dysfunctional organelles during stresses. Increasing evidence shows that autophagy malfunction is associated with many human diseases, such as cancer, neurodegenerative diseases, liver diseases, and inflammatory diseases (78-80). As we know, pathogenassociated molecular patterns (PAMPs) may activate autophagy via regulation of mTORC1 and AMPK. Based on the critical role of mTOR in the regulation of autophagy, it is our belief that SESN2 is closely related to autophagy. Many studies have revealed that SESN2 can regulate autophagy by modulating the mTORC1/AMPK pathway in various cells $(81,82)$.

For example, SESN2, a novel positive modulator of autophagy, was increased in p53-sufficient cells but not in p53-deficient cells when treated by different autophagy inductors, and knockdown of SESN2 decreased the induction of autophagy (83). Hou et al. (84) reported that in a rotenone-induced Parkinson's disease model, the mRNA and protein levels of SESN2 were significantly upregulated in a p53-dependent manner and that silencing of SESN2 suppressed autophagy while increasing the accumulation of autophagy substrates, which manifested as downregulation of light chain 3II (LC3II), exacerbation of p62 accumulation, and inhibition of AMPK phosphorylation. In contrast, overexpression of SESN2 could enhance autophagy activity, as evidenced by enhanced phosphorylation of AMPK and p62 or $\alpha$-synuclein degradation, thereby protecting cells from rotenone cytotoxicity insults. These results indicate that SESN2 is involved in the regulation of autophagy, which might be closely associated with AMPK phosphorylation. Although it has been reported that SESN2 could regulate MTOR via the AMPKTSC2 pathway and Rag GTPase, the mechanisms by which SESN2 modulates autophagy activity remain to be elucidated.

Recently, Ro et al. (85) reported that Unc-51-like protein kinase 1 (ULK1) and p62 were new binding partners for SESN2 and that SESN2 was physically associated with the Cterminal domain of ULK1 to provoke its function. Moreover, SESN2 could interact with the ULK1-Atg13-FIP200 complex to promote p62 phosphorylation, which contributed to eliminating malfunctioning mitochondria and ubiquitinated proteins and modulating the Keap1-Nrf2 pathway. Therefore, the induction of autophagy can markedly enhance SESN2 expression, and SESN2 interacts with multiple autophagy-related proteins to modulate autophagy activity. 


\section{ER Stress}

The ER is highly sensitive to alterations and disturbances in ER homeostasis associated with human diseases. The unfolded protein response (UPR), triggered by the accumulation of unfolded or misfolded proteins within the lumen of ER in various stresses, determines the cell destiny by adjusting the balance between cell adaption to stress and cell death (86, 87). The UPR has evolved at least three branches involving PER-like ER kinase (PERK)-eukaryotic translation initiation factor $2 \alpha($ IF $2 \alpha)$, inositol-requiring enzyme 1 (IRE1)-X-box binding protein 1 (XBP1), and ATF6, and all three pathways can be triggered by different stresses to restore protein-folding homeostasis and regulate ER homeostasis (88).

Currently, increasing data have demonstrated that SESN2 can be upregulated under the ERS response and has a protective effect on ERS-associated diseases $(14,15,32,89)$. For instance, Bruning et al. (89) found that in cancer cells, ERS-upregulated SESN2 was associated with the transcription factor ATF4 and that in return SESN2 inhibited the main regulatory components of the mTOR complex to regulate autophagy homeostasis. Under glucose deprivation, SESN2 was augmented through ERS induction and mechanistically via the transcription factors ATF4 and Nrf2 activation but not via p53. SESN2 protected cell viability and cell death against glucose deprivation through regulation of cellular energy metabolism and mitochondrial homeostasis (54). Similarly, in a methionine/choline-deficient diet-induced hepatic steatosis model, SESN2 expression could be enhanced in a manner that was dependent on the PERK/eIF2 $\alpha /$ ATF4 pathway, and it ameliorated hepatic steatosis progression through autophagy activation (16). In agreement with these findings, a study by Saveljeva et al. (55) revealed that the PERK/eIF2 $\alpha /$ ATF4 and IRE1/XBP1 pathways of the UPR were responsible for ERSinduced SESN2 expression in a p53-independent manner, and knockdown of perk or xbp1 in MCF7 and HCC1806 cells reduced SESN2 expression. In addition, SESN2 deficiency significantly exacerbated persistent protein synthesis and the extent of ERS, inhibited ERS-induced autophagy, and augmented ERS-related cell death.

Furthermore, Jegal et al. (15) elucidated that ERS-induced SESN2 expression was dependent on the ATF6 transcription factor in hepatocytes and that in turn overexpression of SESN2 alleviated ERS-mediated cytotoxicity and attenuated liver damage by downregulation of phosphorylation of JNK and p38 MAPK and cleavage of PARP both in vitro and in vivo. Taken together, these transduction pathways are involved in the enhancement of SESN2 during ERS, and SESN2 might serve as an important regulator that exerts homeostatic feedback to attenuate the ERS response or ERS-induced cell death. These studies highlight the pivotal pro-survival role of SESN2 during cell stress. The signaling pathways that interconnect the regulation between SESN2 and ERS are shown in Figure 3.

\section{Inflammasomes}

Jurg Tschopp's group first presented the concept of inflammasomes in 2002, and inflammasomes are complexes of multiple proteins that can activate caspase-1 and cause maturation of the substrates IL-1 $\beta$ and IL-18 (90). It is wellknown that IL-1 $\beta$ and IL-18 act on various immune cells to regulate the immune response. The hyperactivation of the inflammasome ultimately leads to inflammation, cell death, and tissue injury. NOD-like receptor (NLR) family, pyrin domain containing 3 (NLRP3) is one of the most comprehensively characterized inflammasome proteins, and its prolonged activation plays an important role in the pathogenesis of diverse inflammatory diseases (91).

It has been reported that SESN2 suppressed the excessive activation of the NLRP3 inflammasome and mitochondrial damage, and silencing of SESN2 exacerbated NLRP3-dependent caspase- 1 activation and the secretion of IL-1 $\beta$ and IL-18 after treatment with lipopolysaccharide (LPS). The inhibitory effect of SESN2 on the inflammasome was related to the maintenance of mitochondrial homeostasis by autophagosome formation and mitophagy activation. Mechanistically, SESN2 promoted perinuclear clustering-damaged mitochondria via mediating the aggregation of SQSTM1 and its binding to Lys63linked ubiquitins on the damaged mitochondrial surface. SESN2 expression could increase ULK1 protein levels and contribute to enhanced mitophagic activity (12).

\section{SESN2 AND IMMUNE CELLS}

The possible role of SESN2 in innate and adaptive immune cells, including monocytes, macrophages, natural killer (NK) cells, and T lymphocytes, has been increasingly recognized $(11,12,17,92)$. The expression and effect of SESN2 on immune cells in response to various stimuli are described in Figure 4.

\section{Macrophages}

Macrophages are essential for the host inflammatory response, and the malfunction or apoptosis of macrophages contributes to the development of immunosuppression and a higher risk of secondary infection. A previous study revealed that DETA$\mathrm{NO}$ and hypoxia induced the expression of SESN2 in primary peritoneal mouse macrophages and RAW264.7 cells in a HIF$1 \alpha$-dependent manner and that SESN2 protected cells from overoxidation damage (70). Hu et al. (93) reported that oxidized low-density lipoprotein (ox-LDL) increased SESN2 expression in RAW264.7 cells, which was mediated by the JNK/c-Jun signaling pathway. SESN2 had a protective effect on ox-LDL-induced ROS production and apoptosis in RAW264.7 cells. In addition, TLR ligands (LPS, polyI:C, or peptidoglycan) upregulated SESN2 induction that was dependent on the activator protein (AP)-1 and Nrf2-ARE pathways, and SESN2 inhibited LPSinduced inflammatory insults (18). Furthermore, in a mouse myocardial infarction (MI) model, SESN2 was elevated in cardiac macrophages and had a negative regulatory effect on the proinflammatory response of M1 macrophages via inhibiting TNF$\alpha$, IL-6, and IL-1 $\beta$ expression, thereby polarizing to the M2 phenotype and alleviating excessive inflammation. Likewise, SESN2 overexpression profoundly suppressed the LPS-mediated inflammatory response of M1 and attenuated post-ischemic myocardial inflammation (94). 


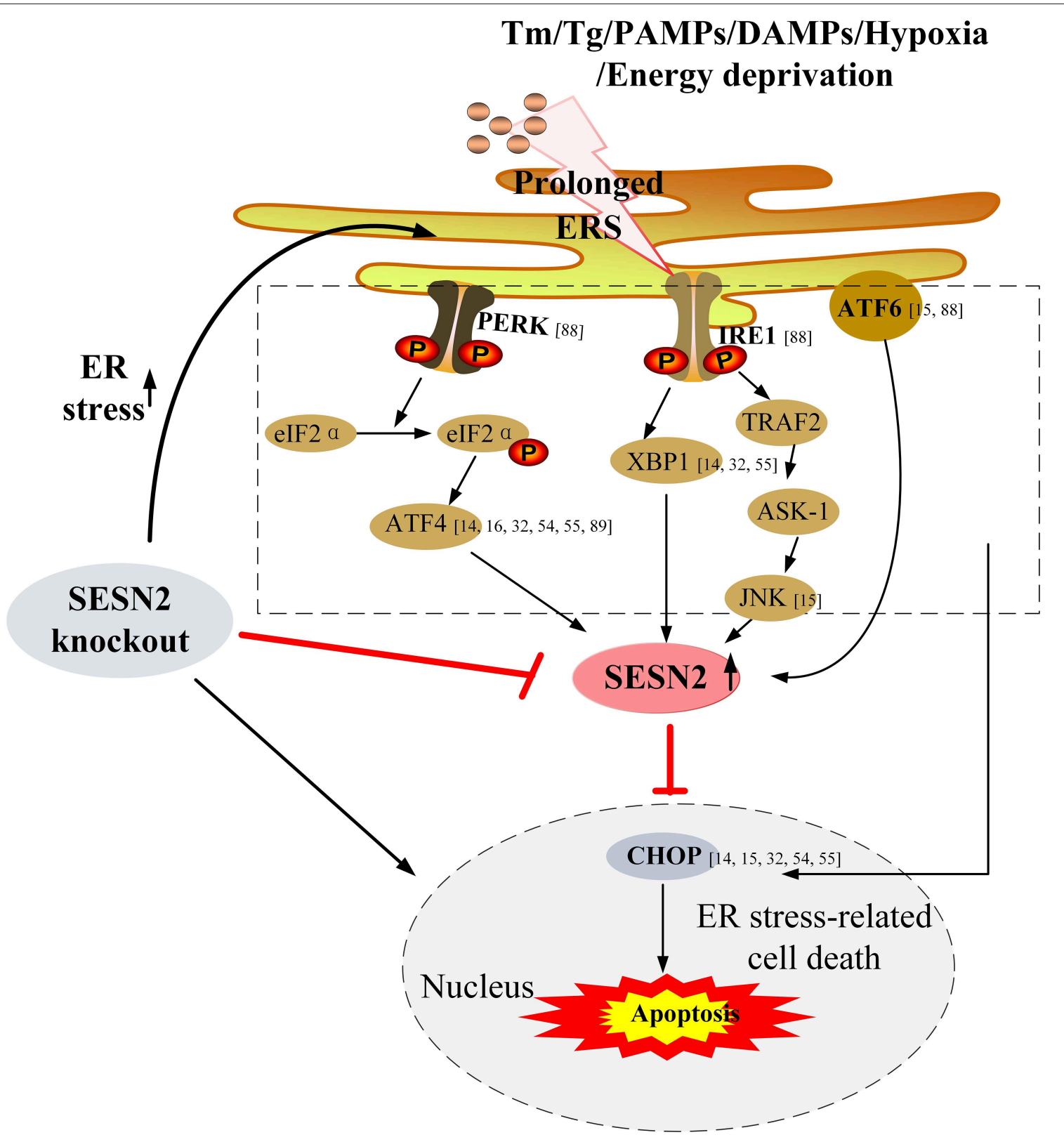

FIGURE 3 | Upregulation of SESN2 under ERS and its protective effect on ERS-associated cell death. Under conditions of stress, ERS is activated due to accumulation of unfolded or misfolded proteins within ER lumen, and then the three branches of the ERS pathway involving PERK (via elF2 $\alpha$ and ATF4), IRE1 (through XBP1, TRAF2, and JNK), and ATF6 upregulate SESN2 expression. SESN2 exerts homeostatic feedback to attenuate the ERS response or ERS-induced cell death. Overexpression of SESN2 reduces ERS-related cell death, while knockout of SESN2 exacerbates the extent of ERS, which results in enhanced ERS-mediated cell apoptosis. Tm, tunicamycin; Tg, thapsigargin; PAMPs, pathogen-associated molecular patterns; DAMPs, damage-associated molecular patterns; PERK, PER-like endoplasmic reticulum kinase; elF2 $\alpha$, eukaryotic translation initiation factor 2 $\alpha$; ATF4, activating transcription factor 4; IRE1, inositol-requiring enzyme 1; XBP1, X-box binding protein 1; TRAF2, TNF- $\alpha$ receptor-associated factor 2; ASK-1, apoptosis signal-regulating kinase 1; JNK, c-Jun N-terminal kinase; ATF6, activating transcription factor 6; CHOP, C/EBP homologous protein.

\section{Monocytes}

It was reported that the human monocytic cell line THP-1 expressed SESN2 in a dose- and time-dependent manner in response to treatment with LPS, and SESN2 knockdown in THP-1 cells significantly augmented LPS-induced nuclear factor (NF) $-\kappa B$ phosphorylation, reduced AMPK phosphorylation, and elevated secretion of pro-inflammatory mediators [TNF- $\alpha$, monocyte chemotactic protein (MCP)-1, and IL-6]. Moreover, SESN2-knockdown mice had higher plasma pro-inflammatory cytokine levels and increased monocyte recruitment to the vascular endothelium by secreting monocyte adhesion molecules [intercellular adhesion molecule (ICAM)-1 and vascular cell 


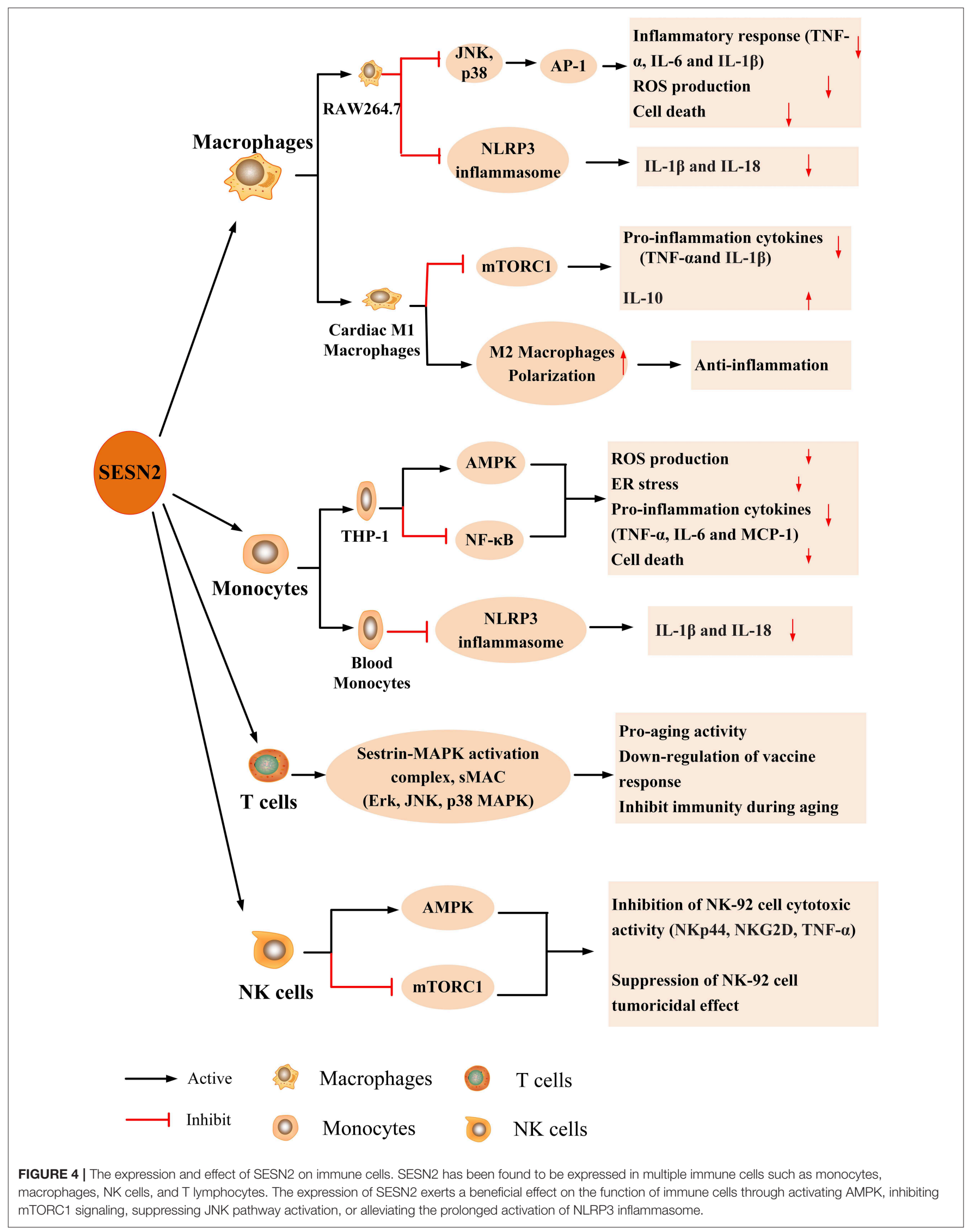


adhesion molecule (VCAM)-1] through inhibiting the AMPK signaling pathway and downregulating the ER stress pathway, which contributed to atherosclerosis initiation (32). Similarly, another study reported that SESN2 regulated monocyte polarization and adhesion to endothelial cells and decreased inflammatory responses by regulating the AMPK-mTOR nexus under high-glucose and dyslipidemic conditions (95). Moreover, in a sepsis mouse model and in septic shock patients, SESN2 levels were increased and peaked at $48 \mathrm{~h}$ in blood monocytes, and SESN2 protected organisms against inflammatory responses and septic shock, which were associated with decreased serum concentrations of IL-1 $\beta$ and IL-18 (12). This study highlighted the protective effect of SESN2 from sepsis and sepsis shock by maintaining mitophagy activation to inhibit NLRP3 inflammasome hyperactivation for immunological homeostasis.

\section{CD4 $^{+} \mathbf{T}$ Lymphocytes}

Recently, Lanna et al. (11) showed that SESN1, SESN2, and SESN3 protein expression was much higher in senescent blood-derived primary human $\mathrm{CD}^{+} \mathrm{T}$ cells than in nonsenescent $\mathrm{T}$ cells and that downregulation of these proteins in senescent $\mathrm{T}$ cells showed antiaging effects, evidenced by the enhancement of cell proliferation, telomerase activity, and IL-2 synthesis. Similarly, SESN expression was much higher in 20-month-old mice than in 2-month-old mice. Notably, SESNs exhibit pro-aging functions in $\mathrm{T}$ cells by binding and activating MAPK pathway members, including ERK, JNK, and p38 MAPK, which are called new SESN-MAPK activation immune-inhibition complexes (sMACs). This effect is opposite to the function of antiaging activities in other cells, which implies some undiscovered mechanisms. In addition, the study revealed that more sMACs were formed in $\mathrm{T}$ cells from older humans (>70-85 years old) and mice (16-20 months old) than in younger humans and mice, and more importantly, the deficiency of SESNs increased splenocytes (T cells and NK cells) and restored immunity and cytokine production in mice after vaccination (11). Recently, Xiao et al. (96) found that in aortic dissection patients, SESN2 was secreted by aortic macrophages and $\mathrm{CD}^{+}{ }^{+} \mathrm{T}$ lymphocytes but not smooth muscle cells (SMCs) and that SESN2 levels were elevated in both plasma and aortas. Moreover, upregulation of SESN2 decreased Ang II-induced SMC apoptosis and attenuated the occurrence and progression of aortic dissection. Although the protective role of SESN2 in cells has been found, further studies are also needed to investigate the possible mechanisms.

\section{Other Immune Cells}

The NK-92 cell line has high tumoral potency and is widely used for immunotherapy in cancer (97). In an ovarian cancer xenograft mouse model, Wang et al. (92) first identified that SESN2 and SESN3 expression was much higher in intratumoral NK-92 cells than in normal human blood NK cells. Overexpression of SESN2 or SESN3 could inhibit NK-92 cellmediated cytotoxic activation through the activation of AMPK and the suppression of mTORC1, which manifested as decreases in the natural cytotoxicity receptors (NKp44 and NKG2D) and cytotoxic factor (TNF- $\alpha$ ) and weakened the antitumor activity of NK-92 cells, emphasizing the potential effect of SESNs on immunotherapy in cancer.

\section{SESN2 AND DISEASES}

Many studies have confirmed the important impact of SESN2 on immune cells, and SESN2 levels are elevated in patients with various diseases, and their plasma levels are positively correlated with the severity of those diseases $(96,98,99)$. Thus, we infer that SESN2 might be an important biomarker and immunotherapeutic target in terms of the diagnosis, treatment, and prognosis of various inflammatory-related diseases. The effects of SESN2 on different diseases are listed in Table 2.

\section{Sepsis}

Sepsis is defined as a life-threatening organ dysfunction caused by a dysregulated host response to infection (104). Immune

TABLE 2 | The effects of SESN2 on various inflammatory-related diseases.

\begin{tabular}{|c|c|c|}
\hline $\begin{array}{l}\text { Inflammatory } \\
\text { disorder }\end{array}$ & Effect & References \\
\hline Sepsis & $\begin{array}{l}\text { Decreasing mortality rate } \\
\text { Attenuating systemic inflammation } \\
\text { Reducing ROS accumulation }\end{array}$ & $(12,17,18)$ \\
\hline Liver diseases & $\begin{array}{l}\text { Protecting liver against hepatitis } \\
\text { Inhibiting TLR-mediated pro-inflammatory } \\
\text { response } \\
\text { Decreasing liver injury } \\
\text { Preventing hepatocyte death, } \\
\text { steatohepatitis, and liver fibrosis } \\
\text { Attenuating obesity-induced hepatic } \\
\text { steatosis } \\
\text { Attenuating glucose intolerance and } \\
\text { insulin resistance }\end{array}$ & $(14-18)$ \\
\hline $\begin{array}{l}\text { Ischemia- } \\
\text { reperfusion } \\
\text { injury }\end{array}$ & $\begin{array}{l}\text { Improving post-ischemic cardiac function } \\
\text { Decreasing heart sensitivity to ischemia } \\
\text { insult } \\
\text { Decreasing heart infarct areas } \\
\text { Maintaining basal cardiac integrity } \\
\text { Ameliorating oxidative stress insult } \\
\text { Alleviating brain infarct areas, attenuating } \\
\text { brain atrophy, lowering neuron apoptosis, } \\
\text { improving the blood-brain barrier integrity, } \\
\text { and improving long-term } \\
\text { neurological function }\end{array}$ & $(20-22,24,100)$ \\
\hline $\begin{array}{l}\text { Neurodegenerative } \\
\text { diseases }\end{array}$ & $\begin{array}{l}\text { Decreasing neuron apoptosis } \\
\text { Attenuating oxidative stress } \\
\text { Alleviating peripheral nerve injury } \\
\text { Inhibiting inflammatory neuropathic pain }\end{array}$ & $(26-28)$ \\
\hline $\begin{array}{l}\text { Cardiovascular } \\
\text { diseases }\end{array}$ & $\begin{array}{l}\text { Inhibiting chronic heart failure } \\
\text { Attenuating smooth muscle cell apoptosis } \\
\text { Delaying the progression of atherosclerosis }\end{array}$ & $(6,32-35,96)$ \\
\hline $\begin{array}{l}\text { Chronic } \\
\text { obstructive } \\
\text { pulmonary disease }\end{array}$ & $\begin{array}{l}\text { Decreasing alveolar maintenance } \\
\text { programs } \\
\text { Alleviating pulmonary emphysema }\end{array}$ & $(36,37,101)$ \\
\hline $\begin{array}{l}\text { Obesity and } \\
\text { diabetes }\end{array}$ & $\begin{array}{l}\text { Maintaining glucose metabolic } \\
\text { homeostasis } \\
\text { Avoiding insulin resistance }\end{array}$ & $(48,102,103)$ \\
\hline Cancer & $\begin{array}{l}\text { Inhibiting cancer cell migration } \\
\text { Inhibiting cancer growth }\end{array}$ & $(41,43)$ \\
\hline
\end{tabular}


dysregulation plays a vital role in the pathophysiological process of sepsis and profoundly influences its high mortality rate $(105,106)$. Recently, reports showed that LPS significantly upregulated the gene and protein expression of SESN2 but not SESN1 in macrophages, such as RAW264.7 cells, mouse bone marrow-derived macrophages (BMDMs), and human THP1 macrophages. The induction of SESN2 markedly prevented cell apoptosis and liver injury from endotoxin toxicity (18). In accordance with this research, Yang et al. (17) found that LPS obviously enhanced SESN2 expression and that upregulation of SESN2 alleviated the inflammatory response by inhibiting the formation of pro-inflammatory cytokines, prevented cell death, and decreased ROS production or oxidative stress insult after LPS stimulation. Therefore, SESN2 can counteract TLR-mediated pro-inflammatory signaling and plays a protective role in LPSinduced inflammatory responses as well as cell death.

In the cecal ligation and puncture (CLP) mouse sepsis model and endotoxemia-induced sepsis model, SESN2 levels were increased, and the more severe the sepsis, the higher the expression of SESN2 and vice versa. Similar to the mouse model, the protein level of human SESN2 was highly upregulated in monocytes in septic shock patients, and the protein level fluctuation was considered to be associated with the serum concentrations of IL-1 $\beta$ and IL-18 in septic patients. Meanwhile, deficiency of SESN2 showed defective mitophagy, caspase1 hyperactivation, and increased secretion of IL-1 $\beta$ and IL18 , which ultimately increased the mortality in murine sepsis (12). These data highlight the protective effect of SESN2 on maintaining inflammatory response and immunological homeostasis during sepsis; however, further investigations should be performed to explore the underlying mechanisms of SESN2 in the pathogenesis of septic complications.

\section{Liver Diseases}

The development and progression of most liver diseases are associated with uncontrolled inflammatory responses resulting in hepatic damage. Growing evidence demonstrates that SESN2 has a marked impact on inflammation-associated pathogenesis of liver diseases $(107,108)$. In D-galactosamine (Gal)/LPS-induced hepatitis, TLR activation participated in SESN2 induction in liver macrophages, and SESN2 attenuated LPS-induced proinflammatory cytokines, hepatic cell death, and liver damage $(17,18)$. It was revealed that SESN2 knockdown mice exhibited an increased number of macrophages, severe hepatocyte death, and extensive liver damage (14). It is likely that SESN2 deficiency provoked high-fat diet (HFD)-mediated hepatic steatosis, hepatic inflammation, and liver fibrosis. In contrast, liver-specific SESN2 reconstitution completely reversed HFDinduced non-alcoholic steatohepatitis and liver damage. In addition, acetaminophen (APAP) caused hepatotoxicity and inflammatory response in mice, whereas administration of AdSESN2 ameliorated APAP-induced hepatocyte degeneration and inflammatory cell infiltration and reduced the mortality rate (13). What's more, Kim et al. (16) found that methionine/cholinedeficient (MCD) diet-fed mice showed hepatic transglutaminase elevation and liver inflammation and damage, while treatment with carbon monoxide ameliorated levels of plasma AST,
ALT, and inflammatory cytokines via increasing SESN2 levels. Knockdown of SESN2 impeded the protective effect of carbon monoxide on the livers of MCD-fed mice. In agreement with these observations, ablation of SESN2 exacerbated acute liver injury or obesity-induced hepatosteatosis, whereas upregulation of SESN2 exhibited a hepatoprotective effect (15). Taken together, these results suggest the pivotal role of SESN2 in the modulation of hepatic homeostasis and inflammation.

\section{Ischemia-Reperfusion Injury}

Ischemia-reperfusion (I/R) injury is a key factor that causes energy metabolism disorders, cell damage, uncontrolled inflammation, and organ dysfunction. Moreover, the major interventions against these damages are alleviation of oxidative stress and attenuation of the inflammatory response and cell apoptosis $(109,110)$.

In a myocardial I/R injury model, Morrison et al. (20) found that SESN2 was significantly increased in murine cardiac tissue during ischemic conditions and that SESN2-knockout mice showed severe myocardial infarct size and post-ischemic cardiac dysfunction. Intriguingly, SESN2 functioned as an ischemicscaffold protein in the AMPK-LKB1 axis, promoting AMPK activation to reduce ischemic injury. In line with this study, Quan et al. (21) determined that the dynamic decline of SESN2 paralleled the increasing sensitivity to ischemic insults in aged hearts. Aged and SESN2-knockout hearts exacerbated I/R-induced cardiac damage, as evidenced by worsened cardiac dysfunction and increased MI size in vivo and in vitro. Rescue of SESN2 significantly improved cardiac function and decreased infarction size in aged hearts subjected to $I / R$ insults. The mechanisms underlying SESN2 in downregulating the sensitivity of aged hearts to ischemic stress were mainly dependent on the interaction with the AMPK signaling pathway to modulate PGC-1 $\alpha$, which could affect mitochondrial biogenesis and attenuate the apoptosis of cardiocytes following ischemic insults (22).

In an acute hypoxia rat model of stroke by permanent middle cerebral artery occlusion (MCAO), Hi95 was highly increased in the rat brain and showed a protective role against ischemia brain injury (3). Likewise, in a transient global I/R rat model, SESN2 was obviously augmented in the hippocampal CA1 subfield, and silencing of SESN2 exacerbated the extent of oxidative stress damage, neuronal injury, and hippocampal neuron apoptosis (23). Consistent with these results, further studies confirmed that SESN2 played a protective role against cerebral I/R injury by alleviating brain infarct areas, attenuating brain atrophy, reducing neuron apoptosis, improving the blood-brain barrier integrity, and improving long-term neurological function (24, $71,100)$. Additionally, SESN2 was increased in cortical renal tubules during I/R-induced acute kidney injury, and p53-SESN2 prevented the I/R damage-induced apoptosis of renal cells by activating autophagy and mitophagy (25).

\section{Neurodegenerative Diseases}

It has been demonstrated that SESN2 contributes to chronic inflammation associated with neurodegenerative diseases, such as Alzheimer's disease ( $\mathrm{AD})$ and Parkinson's disease (PD). 
SESN2 was upregulated in primary rat cortical neurons treated with amyloid- $\beta / \mathrm{A} \beta$ (a hallmark of $\mathrm{AD}$-caused cytotoxicity and neuronal death) both in vitro and in vivo, and that elimination of SESN2 exacerbated $A \beta$-induced neurotoxicity, which indicated that SESN2 upregulation by $A \beta$ positively modulated autophagy to protect against neurotoxicity (26). A clinical study showed that the expression of SESN2 was altered in brains with human immunodeficiency virus (HIV)-associated neurocognitive disorders (HAND). SESN2 was mainly located in neuronal soma in cases of HAND, whereas it colocalized with pTau in neurofibrillary lesions in $\mathrm{AD}$ brains, showing a protective role against neuronal oxidative stress (27). Another clinical study documented that SESN2 levels were more highly increased in the serum of $\mathrm{AD}$ patients whose disease course was $<2$ years when compared to patients with mild cognitive impairment or elderly patients older than 60 years of age, suggesting a potential application as an early protein marker for the detection of $\mathrm{AD}$ (28). In accordance with the findings obtained from the model of $\mathrm{AD}$, adoption of a PD model by Hou et al. (84) indicated that SESN2 enhanced autophagy activity and inhibited cell death in a PD model in vitro. Additionally, it has been reported that SESN2 expression is increased in both patients with PD and a 1-methyl-4-phenylpyridinium (MPP+)-induced PD cell model and that SESN2 plays a protective role against MPP + -induced neurotoxicity by regulating mitochondrial function, oxidative stress, and cell apoptosis (111). These results indicate that SESN2 has a protective effect on neurodegenerative diseases.

\section{Cardiovascular Diseases}

Cardiovascular diseases belong to age-related pathologies, and inflammatory conditions are one of the characteristics of these diseases. Studies have shown that SESN2 plays a pivotal role in the occurrence and development of various cardiac pathophysiologies. As reported, SESN2 levels were elevated in patients with chronic heart failure, coronary artery diseases, aortic dissection, and atrial fibrillation (96, 99, 112, 113). Lee et al. (6) originally described the regulatory function of SESNs in heart function. They further demonstrated that loss of dSESN was associated with age-associated pathologies, such as cardiac malfunction, muscle degeneration, and triglyceride accumulation. One mechanism by which SESN2 affected cardiac function is related to its beneficial effect against cardiomyocyte hypertrophy. As reported, in a phenylephrineinduced hypertrophy model, SESN2 expression was decreased in the process of cardiac hypertrophy, and SESN2 retarded the cardiomyocyte hypertrophy process by inhibiting ERK1/2 signaling (33). And another mechanism of SESN2 protecting against cardiac remodeling is via enhancing its antioxidant effect on the Nrf2-Keap1 pathway (34). What's more, in human umbilical vein endothelial cells, treatment with angiotensin (Ang) II increased SESN2 expression, and knockdown of SESN2 exacerbated Ang II-induced toxicity (35). Similarly, SESN2 attenuated Ang II-induced apoptosis of SMCs via regulating the Nrf2 pathway and decreased the occurrence of aortic dissection (96).

Moreover, in an atherosclerosis model, SESN2 protected blood vessels by decreasing the formation of atherosclerotic plaques or other hallmarks in endothelial cells (32). Chronic inflammation precedes atherosclerosis progression, and SESN2 prevented the development of atherosclerosis by activating the AMPK pathway and then by reducing inflammation response. Taken together, SESN2 might be a beneficial target for amelioration of cardiovascular diseases, indicating its potential therapeutic role in cardiovascular diseases.

\section{Chronic Obstructive Pulmonary Disease}

Chronic obstructive pulmonary disease (COPD) is characterized by chronic inflammatory and immune responses mainly from the small airways to lung parenchyma, and aberrant immunity and oxidant/antioxidant imbalance might be the central pathway in the pathogenesis of COPD $(114,115)$.

In the mouse model of COPD, Wempe et al. (36) found that inactivation of SESN2 protein decreased airways and elastic fiber fragmentation of alveolar walls, rescued pulmonary emphysema, and improved pulmonary function via selectively activating transforming growth factor- $\beta$ signaling. Similarly, SESN2 was significantly upregulated in emphysematous lungs of patients with advanced COPD, and SESN2-knockout mice increased alveolar maintenance and reduced cigarette smoke-induced pulmonary emphysema by enhancing the expression of platelet-derived growth factor receptor $\beta$ (37). Mechanistically, SESN2 inhibited platelet-derived growth factor receptor $\beta$-mediated lung regeneration and injury repair by promoting autophagic degradation of Keap1 to activate the Nrf2-Keap1 pathway that protected against pulmonary emphysema $(101,116)$. Therefore, SESN2 serves as a negative regulator and a biomarker in the development of COPD, and COPD patients might benefit from SESN2 antagonists in clinical management.

\section{Metabolic-Related Diseases Obesity and Diabetes}

Metabolic disorders such as diabetes and obesity are associated with mTORC1 activation (117), and inflammation seems to be involved in the biological process of these diseases (118). Obesity can cause glucose intolerance and insulin resistance. Recently, it was found that SESN2 was upregulated upon hypernutrition and obesity in mouse liver, which was critical for maintaining glucose metabolic homeostasis in hepatocytes, and that deficiency of SESN2 exacerbated obesity-induced hepatosteatosis. Knockout of SESN2 exacerbated obesity-induced insulin resistance and diabetic progression, which were associated with impaired glucose homeostasis and reduced insulin sensitivity (48). Similarly, Chai et al. (102) reported that insulin obviously increased SESN2 expression in mouse primary hepatic cells and hepatic tumor cell lines, which was related to attenuation of proteasome-mediated SESN2 degradation. Thus, SESN2 showed a negative feedback effect on insulin signaling transduction (103).

\section{Cancer}

Inflammation is a hallmark in the development and progression of cancer, and cancer-related inflammation fosters the initiation and growth of cancers (119). Recent studies have indicated that a low level of SESN2 is associated with progression 
and poor prognosis in different types of cancer patients or tumor models. It was reported that SESN2 acted as a potential suppressor in the colon during intestinal inflammation and colon cancer progression and contributed to maintaining intestinal homeostasis. SESN2-deficient mice had accelerated colonic epithelial cell apoptosis and inflammation during colitis. Moreover, SESN2 was strongly decreased in colon adenocarcinoma tissues, and its expression was downregulated in correlation with the progression of colon cancer. Loss of SESN2 promoted colon cancer growth and reduced susceptibility to chemotherapeutic treatments, as evidenced by dramatically increased tumor size and burden (40). In addition, Seo et al. (41) reported that SESN2 played a beneficial role in inhibiting colorectal cancer cell migration in vitro.

More recently, Liang et al. (42) found that SESN2 was significantly decreased in human bladder cancer cells, that isorhapontigenin could upregulate SESN2 expression in a MAPK8-JUN-dependent manner, and that SESN2 induction could inhibit human bladder cancer growth by activating autophagy. Additionally, SESN2 expression was lower in hepatocellular carcinoma tissues than in non-cancerous tissues, and low SESN2 levels were related to positive lymph node metastasis, advanced tumors, and poor prognosis in hepatocellular carcinoma patients (43). Mechanistically, SESN2 inhibited hepatocyte proliferation and carcinoma development by activating the Nrf2 pathway and suppressing the mTOR pathway (44). Collectively, SESN2 has anticancer effects, and modulation of SESN2 expression might contribute to the treatment and prognosis of cancers.

\section{Aging}

Accumulation of ROS and activation of mTORC1 are general features of aging and age-associated disorders. As SESN2 has antioxidant property and mTORC1 suppression ability, it seems plausible that SESN2 could modulate aging and age-related diseases. It has been reported that a p53-overexpressing mice model accompanied with the elevated expression of SESN1 and SESN2 could delay aging-associated damage and increase longevity (120). Additionally, dSESN inactivation resulted in the reduction of health span and acceleration of age-related tissue degeneration including muscle degeneration, cardiac dysfunction, and lipid accumulation by preventing excessive ROS accumulation and TORC1 activation (6). Moreover, in Caenorhabditis elegans, SESN1, the only SESN ortholog, acted as a positive modulator of health span, and a mutant of SESN1 showed muscle dysregulation (47). Given all of the above, we confer that SESN2 might provide a key feedback modulation of aging-associated pathologies. And it will be interesting to

\section{REFERENCES}

1. Buckbinder L, Talbott R, Seizinger BR, Kley N. Gene regulation by temperature-sensitive p53 mutants: identification of p53 response genes. Proc Natl Acad Sci USA. (1994) 91:10640-4. doi: 10.1073/pnas.91.22. 10640

2. Velasco-Miguel S, Buckbinder L, Jean P, Gelbert L, Talbott R, Laidlaw J, et al. PA26, a novel target of the p53 tumor suppressor and member of the GADD ascertain the contribution of SESN2 to these antiaging functions in further investigations.

\section{CONCLUSIONS AND PERSPECTIVES}

SESN2 is regarded as a stress-induced protein, and substantial evidence has demonstrated its vital effect in regulating diverse cellular functions, including cell fate, energy metabolism, inflammation, liver diseases, and carcinogenesis. Over the past two decades, tremendous progress has been made toward understanding the biological structure and functions of SESN2 in physiopathology, but certain limitations remain. Firstly, SESN family members share high sequence homology, which might have redundant functions. However, there is a lack of studies on SESN1 and SESN3, and it will be important for future studies to identify similarities and differences between the biochemical functions of the SESN family under different stress conditions. Additionally, the potential role of SESN2 in classical inflammatory diseases, including sepsis, is still uncertain; thus, the biochemical and biological basis of SESN2 requires a better understanding, and the precise molecular mechanism by which SESN2 regulates the inflammatory process remains to be investigated. More importantly, as most studies are based on cell culture or animal models, to what extent these findings are applicable to humans is still unclear. Further studies on the upstream and downstream regulators of SESN2 may contribute to a deep understanding of the biological, physiological, and pathophysiological effects of SESN2 in various inflammatory disorders. It will be necessary to use SESN2 transgenic or SESN2-deficient animal models and carry out more clinical trials to clarify the mechanisms by which SESN2 elicits protective responses and may serve as a drug target in the prevention and treatment of inflammatory diseases.

\section{AUTHOR CONTRIBUTIONS}

L-XW drafted the manuscript. X-MZ revised the manuscript. Y-MY contributed to the conception of the review and helped perform the constructive discussions.

\section{FUNDING}

This work was supported by grants from the National Natural Science Foundation of China (Nos. 81730057, 81871557, and 81842025), the Key Project of Military Medical Innovation Program of Chinese PLA (No. 18CXZ026), and the National Key Research and Development Program of China (No. 2017YFC1103302). family of DNA damage and growth arrest inducible genes. Oncogene. (1999) 18:127-37. doi: 10.1038/sj.onc.1202274

3. Budanov AV, Shoshani T, Faerman A, Zelin E, Kamer I, Kalinski H, et al. Identification of a novel stress-responsive gene Hi95 involved in regulation of cell viability. Oncogene. (2002) 21:6017-31. doi: 10.1038/sj.onc.1205877

4. Budanov AV, Sablina AA, Feinstein E, Koonin EV, Chumakov PM. Regeneration of peroxiredoxins by p53-regulated sestrins, homologs of bacterial AhpD. Science. (2004) 304:596-600. doi: 10.1126/science.1095569 
5. Budanov AV, Karin M. p53 target genes sestrin1 and sestrin2 connect genotoxic stress and mTOR signaling. Cell. (2008) 134:451-60. doi: 10.1016/j.cell.2008.06.028

6. Lee JH, Budanov AV, Park EJ, Birse R, Kim TE, Perkins GA, et al. Sestrin as a feedback inhibitor of TOR that prevents age-related pathologies. Science. (2010) 327:1223-8. doi: 10.1126/science.1182228

7. Peng M, Yin N, Li M. Sestrins function as guanine nucleotide dissociation inhibitors for Rag GTPases to control mTORC1 signaling. Cell. (2014) 159:122-33. doi: 10.1016/j.cell.2014.08.038

8. Chantranupong L, Wolfson RL, Orozco JM, Saxton RA, Scaria SM, BarPeled L, et al. The sestrins interact with GATOR2 to negatively regulate the amino-acid-sensing pathway upstream of mTORC1. Cell Rep. (2014) 9:1-8. doi: 10.1016/j.celrep.2014.09.014

9. Budanov AV, Lee JH, Karin M. Stressin' sestrins take an aging fight. $E M B O$ Mol Med. (2010) 2:388-400. doi: 10.1002/emmm.201000097

10. Nogueira V, Park Y, Chen CC, Xu PZ, Chen ML, Tonic I, et al. Akt determines replicative senescence and oxidative or oncogenic premature senescence and sensitizes cells to oxidative apoptosis. Cancer Cell. (2008) 14:458-70. doi: 10.1016/j.ccr.2008.11.003

11. Lanna A, Gomes DC, Muller-Durovic B, McDonnell T, Escors D, Gilroy DW, et al. A sestrin-dependent ERK-JNK-p38 MAPK activation complex inhibits immunity during aging. Nat Immunol. (2017) 18:354-63. doi: $10.1038 /$ ni.3665

12. Kim MJ, Bae SH, Ryu JC, Kwon Y, Oh JH, Kwon J, et al. SESN2/sestrin2 suppresses sepsis by inducing mitophagy and inhibiting NLRP3 activation in macrophages. Autophagy. (2016) 12:1272-91. doi: 10.1080/15548627.2016.1183081

13. Kim SJ, Kim KM, Yang JH, Cho SS, Kim JY, Park SJ, et al. Sestrin2 protects against acetaminophen-induced liver injury. Chem Biol Inter. (2017) 269:508. doi: 10.1016/j.cbi.2017.02.002

14. Park HW, Park H, Ro SH, Jang I, Semple IA, Kim DN, et al. Hepatoprotective role of sestrin2 against chronic ER stress. Nat Commun. (2014) 5:4233. doi: $10.1038 /$ ncomms5233

15. Jegal KH, Park SM, Cho SS, Byun SH, Ku SK, Kim SC, et al. Activating transcription factor 6-dependent sestrin 2 induction ameliorates ER stress-mediated liver injury. Biochim Biophys Acta. (2017) 1864:1295-307. doi: 10.1016/j.bbamcr.2017.04.010

16. Kim HJ, Joe Y, Kim SK, Park SU, Park J, Chen Y, et al. Carbon monoxide protects against hepatic steatosis in mice by inducing sestrin-2 via the PERK-eIF2 $\alpha$-ATF4 pathway. Free Radic Biol Med. (2017) 110:81-91. doi: 10.1016/j.freeradbiomed.2017.05.026

17. Yang JH, Kim KM, Kim MG, Seo KH, Han JY, Ka SO, et al. Role of sestrin2 in the regulation of proinflammatory signaling in macrophages. Free Radic Biol Med. (2015) 78:156-67. doi: 10.1016/j.freeradbiomed.2014.11.002

18. Kim MG, Yang JH, Kim KM, Jang CH, Jung JY, Cho IJ, et al. Regulation of Toll-like receptor-mediated sestrin2 induction by AP-1, Nrf2, and the ubiquitin-proteasome system in macrophages. Toxicol Sci. (2015) 144:42535. doi: $10.1093 /$ toxsci/kfv012

19. Huang M, Kim HG, Zhong X, Dong C, Zhang B, Fang Z, et al. Sestrin 3 protects against diet-induced nonalcoholic steatohepatitis in mice through suppression of transforming growth factor $\beta$ signal transduction. Hepatology. (2019). doi: 10.1002/hep.30820. [Epub ahead of print].

20. Morrison A, Chen L, Wang J, Zhang M, Yang H, Ma Y, et al. Sestrin2 promotes LKB1-mediated AMPK activation in the ischemic heart. FASEB J. (2015) 29:408-17. doi: 10.1096/fj.14-258814

21. Quan N, Sun W, Wang L, Chen X, Bogan JS, Zhou X, et al. Sestrin2 prevents age-related intolerance to ischemia and reperfusion injury by modulating substrate metabolism. FASEB J. (2017) 31:4153-67. doi: 10.1096/fj.201700063R

22. Quan N, Wang L, Chen X, Luckett C, Cates C, Rousselle T, et al. Sestrin2 prevents age-related intolerance to post myocardial infarction via AMPK/PGC-1 $\alpha$ pathway. J Mol Cell Cardiol. (2018) 115:170-8. doi: 10.1016/j.yjmcc.2018.01.005

23. Chuang YC, Yang JL, Yang DI, Lin TK, Liou CW, Chen SD. Roles of sestrin2 and ribosomal protein $s 6$ in transient global ischemiainduced hippocampal neuronal injury. Int J Mol Sci. (2015) 16:26406-16. doi: $10.3390 /$ ijms 161125963
24. Li L, Xiao L, Hou Y, He Q, Zhu J, Li Y, et al. Sestrin2 silencing exacerbates cerebral ischemia/reperfusion injury by decreasing mitochondrial biogenesis through the AMPK/PGC-1 $\alpha$ pathway in rats. Sci Rep. (2016) 6:30272. doi: $10.1038 /$ srep30272

25. Ishihara M, Urushido M, Hamada K, Matsumoto T, Shimamura $Y$, Ogata $\mathrm{K}$, et al. Sestrin-2 and BNIP3 regulate autophagy and mitophagy in renal tubular cells in acute kidney injury. Am J Physiol Renal Physiol. (2013) 305:F495-F509. doi: 10.1152/ajprenal.00642.2012

26. Chen YS, Chen SD, Wu CL, Huang SS, Yang DI. Induction of sestrin2 as an endogenous protective mechanism against amyloid beta-peptide neurotoxicity in primary cortical culture. Exp Neurol. (2014) 253:63-71. doi: 10.1016/j.expneurol.2013.12.009

27. Soontornniyomkij V, Soontornniyomkij B, Moore DJ, Gouaux B, Masliah E, Tung S, et al. Antioxidant sestrin-2 redistribution to neuronal soma in human immunodeficiency virus-associated neurocognitive disorders. $J$ Neuroimmune Pharmacol. (2012) 7:579-90. doi: 10.1007/s11481-012-9357-0

28. Rai N, Kumar R, Desai GR, Venugopalan G, Shekhar S, Chatterjee P, et al. Relative alterations in blood-based levels of Sestrin in Alzheimer's disease and mild cognitive impairment patients. J Alzheimers Dis. (2016) 54:1147-55. doi: 10.3233/JAD-160479

29. Wu CL, Chen SD, Yin JH, Hwang CS, Yang DI. Nuclear factor-kappabdependent sestrin2 induction mediates the antioxidant effects of bdnf against mitochondrial inhibition in rat cortical neurons. Mol Neurobiol. (2016) 53:4126-42. doi: 10.1007/s12035-015-9357-1

30. Johnson MR, Behmoaras J, Bottolo L, Krishnan ML, Petretto E. Systems genetics identifies sestrin 3 as a regulator of a proconvulsant gene network in human epileptic hippocampus. Nat Commun. (2015) 6:6031. doi: 10.1038/ncomms7031

31. Xue R, Zeng J, Chen Y, Chen C, Tan W, Zhao J, et al. Sestrin 1 ameliorates cardiac hypertrophy via autophagy activation. J Cell Mol Med. (2017) 21:1193-205. doi: $10.1111 / \mathrm{jcmm} .13052$

32. Hwang HJ, Jung TW, Choi JH, Lee HJ, Chung HS, Seo JA, et al. Knockdown of sestrin2 increases pro-inflammatory reactions and ER stress in the endothelium via an AMPK dependent mechanism. Biochim Biophys Acta. (2017) 1863:1436-44. doi: 10.1016/j.bbadis.2017.02.018

33. Dong B, Xue R, Sun Y, Dong Y, Liu C. Sestrin 2 attenuates neonatal rat cardiomyocyte hypertrophy induced by phenylephrine via inhibiting erk1/2. Mol Cell Biochem. (2017) 433:113-23. doi: 10.1007/s11010-017-3020-2

34. Du JX, Wu JZ, Li Z, Zhang C, Shi MT, Zhao J, et al. Pentamethylquercetin protects against cardiac remodeling via activation of Sestrin2. Biochem Biophys Res Commun. (2019) 512:412-20. doi: 10.1016/j.bbrc.2019.03.031

35. Yi L, Li F, Yong Y, Jianting D, Liting Z, Xuansheng H, et al. Upregulation of sestrin-2 expression protects against endothelial toxicity of angiotensin II. Cell Biol Toxicol. (2014) 30:147-56. doi: 10.1007/s10565-014-9276-3

36. Wempe F, De-Zolt S, Koli K, Bangsow T, Parajuli N, Dumitrascu R, et al. Inactivation of sestrin 2 induces TGF- $\beta$ signaling and partially rescues pulmonary emphysema in a mouse model of COPD. Dis Models Mech. (2010) 3:246-53. doi: 10.1242/dmm.004234

37. Heidler J, Fysikopoulos A, Wempe F, Seimetz M, Bangsow T, Tomasovic A, et al. Sestrin-2, a repressor of PDGFR $\beta$ signaling, promotes cigarette-smokeinduced pulmonary emphysema in mice and is upregulated in individuals with COPD. Dis Models Mech. (2013) 6:1378-87. doi: 10.1242/dmm.013482

38. Zhang L, Liu W, Wang Q, Li Q, Wang H, Wang J, et al. New drug candidate targeting the $4 \mathrm{Al}$ orphan nuclear receptor for medullary thyroid cancer therapy. Molecules. (2018) 23, 565. doi: 10.3390/molecules 23030565

39. Oricchio E, Katanayeva N, Donaldson MC, Sungalee S, Pasion JP, Béguelin $\mathrm{W}$, et al. Genetic and epigenetic inactivation of SESTRIN1 controls mTORC1 and response to EZH2 inhibition in follicular lymphoma. Sci Transl Med. (2017) 9:eaak9969. doi: 10.1126/scitranslmed.aak9969

40. Ro SH, Xue X, Ramakrishnan SK, Cho CS, Namkoong S, Jang I, et al. Tumor suppressive role of sestrin2 during colitis and colon carcinogenesis. Elife. (2016) 5:e12204. doi: 10.7554/eLife.12204.001

41. Seo K, Ki SH, Park EY, Shin SM. 5-Fluorouracil inhibits cell migration by induction of Sestrin2 in colon cancer cells. Archiv Pharm Res. (2017) 40:231-9. doi: 10.1007/s12272-016-0878-6.

42. Liang Y, Zhu J, Huang H, Xiang D, Li Y, Zhang D, et al. SESN2/sestrin 2 induction-mediated autophagy and inhibitory effect of isorhapontigenin 
(ISO) on human bladder cancers. Autophagy. (2016) 8:1229-39. doi: 10.1080/15548627.2016.1179403

43. Chen S, Yan W, Lang W, Yu J, Xu L, Xu X, et al. SESN2 correlates with advantageous prognosis in hepatocellular carcinoma. Diagnost Pathol. (2017) 12:13. doi: 10.1186/s13000-016-0591-2

44. Buitrago-Molina LE, Marhenke S, Longerich T, Sharma AD, Boukouris AE, Geffers R, et al. The degree of liver injury determines the role of p21 in liver regeneration and hepatocarcinogenesis in mice. Hepatology. (2013) 58:1143-52. doi: 10.1002/hep.26412

45. Vakana E, Arslan AD, Szilard A, Altman JK, Platanias LC. Regulatory effects of Sestrin 3 (SESN3). in BCR-ABL expressing cells. PLoS ONE. (2013) 8:e78780. doi: 10.1371/journal.pone.0078780

46. Khan N, Jajeh F, Khan MI, Mukhtar E, Shabana SM, Mukhtar H. Sestrin3 modulation is essential for therapeutic efficacy of cucurbitacin b in lung cancer cells. Carcinogenesis. (2017) 38:184-95. doi: 10.1093/carcin/bgw124

47. Yang YL, Loh KS, Liou BY, Chu IH, Kuo CJ, Chen HD, et al. SESN-1 is a positive regulator of lifespan in Caenorhabditis elegans. Exp Gerontol. (2013) 48:371-9. doi: 10.1016/j.exger.2012.12.011

48. Lee JH, Budanov AV, Talukdar S, Park EJ, Park HL, Park HW, et al. Maintenance of metabolic homeostasis by Sestrin2 and Sestrin3. Cell Metab. (2012) 16:311-21. doi: 10.1016/j.cmet.2012.08.004

49. Chen CC, Jeon SM, Bhaskar PT, Nogueira V, Sundararajan D, Tonic I, et al. FoxOs inhibit mTORC1 and activate Akt by inducing the expression of sestrin3 and Rictor. Dev Cell. (2010) 18:592-604. doi: 10.1016/j.devcel.2010.03.008

50. Saxton RA, Knockenhauer KE, Wolfson RL, Chantranupong L, Pacold ME, Wang T, et al. Structural basis for leucine sensing by the Sestrin2-mTORC1 pathway. Science. (2016) 351:53-8. doi: 10.1126/science.aad2087

51. Ho A, Cho CS, Namkoong S, Cho US, Lee JH. Biochemical basis of sestrin physiological activities. Trends Biochem Sci. (2016) 41:621-32. doi: 10.1016/j.tibs.2016.04.005

52. Kim H, An S, Ro SH, Teixeira F, Park GJ, Kim C, et al. Janus-faced sestrin2 controls ROS and mTOR signaling through two separate functional domains. Nat Commun. (2015) 6:10025. doi: 10.1038/ncomms10025

53. Shin BY, Jin SH, Cho IJ, Ki SH. Nrf2-ARE pathway regulates induction of sestrin2 expression. Free Radic Biol Med. (2012) 53:834-41. doi: 10.1016/j.freeradbiomed.2012.06.026

54. Ding B, Parmigiani A, Divakaruni AS, Archer K, Murphy AN, Budanov AV. Sestrin2 is induced by glucose starvation via the unfolded protein response and protects cells from non-canonical necroptotic cell death. Sci Rep. (2016) 6:22538. doi: 10.1038/srep22538

55. Saveljeva S, Cleary P, Mnich K, Ayo A, Pakos-Zebrucka K, Patterson JB, et al. Endoplasmic reticulum stress-mediated induction of sestrin2 potentiates cell survival. Oncotarget. (2016) 7:12254-66. doi: 10.18632/oncotarget.7601

56. Ben-Sahra I, Dirat B, Laurent K, Puissant A, Auberger P, Budanov A, et al. Sestrin2 integrates Akt and mTOR signaling to protect cells against energetic stress-induced death. Cell Death Differ. (2013) 20:611-9. doi: 10.1038/cdd.2012.157

57. Lee JH, Budanov AV, Karin M. Sestrins orchestrate cellular metabolism to attenuate aging. Cell Metab. (2013) 18:792-801. doi: 10.1016/j.cmet.2013.08.018

58. Lee JH, Bodmer R, Bier E, Karin M. Sestrins at the crossroad between stress and aging. Aging. (2010) 2:369-74. doi: 10.18632/aging.100157

59. Shimizu I, Yoshida Y, Suda M, Minamino T. DNA damage response and metabolic disease. Cell Metab. (2014) 20:967-77. doi: 10.1016/j.cmet.2014.10.008

60. Mlitz V, Gendronneau G, Berlin I, Buchberger M, Eckhart L, Tschachler E. The expression of the endogenous mTORC1 inhibitor sestrin 2 is induced by UVB and balanced with the expression level of sestrin1. PLoS ONE. (2016) 11:e0166832. doi: 10.1371/journal.pone.0166832

61. Zhao B, Shah P, Qiang L, He TC, Budanov A, He YY. Distinct role of Sesn2 in response to UVB-induced DNA damage and UVA-induced oxidative stress in melanocytes. Photochem Photobiol. (2017) 93:375-81. doi: $10.1111 /$ php. 12624

62. Jayaraj P, Sen S, Rangarajan S, Ray N, Vasu K, Singh VK, et al. Immunohistochemical evaluation of stress-responsive protein sestrin2 and its correlation with p53 mutational status in eyelid sebaceous gland carcinoma. Br J Ophthalmol. (2018) 102:848-54. doi: 10.1136/bjophthalmol-2017-311283

63. Duračková Z. Some current insights into oxidative stress. Physiol Res. (2010) 59:459-69.

64. Suzuki T, Motohashi H, Yamamoto M. Toward clinical application of the Keap1-Nrf2 pathway. Trends Pharmacol Sci. (2013) 34:340-6. doi: 10.1016/j.tips.2013.04.005

65. Bae SH, Sung SH, Oh SY, Lim JM, Lee SK, Park YN, et al. Sestrins activate Nrf2 by promoting p62-dependent autophagic degradation of Keap1 and prevent oxidative liver damage. Cell Metab. (2013) 17:73-84. doi: 10.1016/j.cmet.2012.12.002

66. Ro SH, Nam M, Jang I, Park HW, Park H, Semple IA, et al. Sestrin2 inhibits uncoupling protein 1 expression through suppressing reactive oxygen species. Proc Natl Acad Sci USA. (2014) 111:7849-54. doi: 10.1073/pnas.1401787111

67. Jegal KH, Ko HL, Park SM, Byun SH, Kang KW, Cho IJ, et al. Eupatilin induces sestrin2-dependent autophagy to prevent oxidative stress. Apoptosis. (2016) 21:642-56. doi: 10.1007/s10495-016-1233-6

68. Ro SH, Semple I, Ho A, Park HW, Lee JH. Sestrin2, a regulator of thermogenesis and mitohormesis in brown adipose tissue. Front Endocrinol. (2015) 6:114. doi: 10.3389/fendo.2015.00114

69. Olson N, Hristova M, Heintz NH, Lounsbury KM, van der Vliet A. Activation of hypoxia-inducible factor-1 protects airway epithelium against oxidant-induced barrier dysfunction. Am J Physiol Lung Cell Mol Physiol. (2011) 301:L993-1002. doi: 10.1152/ajplung.00250.2011

70. Essler S, Dehne N, Brüne B. Role of sestrin2 in peroxide signaling in macrophages. FEBS Lett. (2009) 583:3531-5. doi: $10.1016 /$ j.febslet.2009.10.017

71. Shi X, Doycheva DM, Xu L, Tang J, Yan M, Zhang JH. Sestrin2 induced by hypoxia inducible factor1 alpha protects the blood-brain barrier via inhibiting VEGF after severe hypoxic-ischemic injury in neonatal rats. Neurobiol Dis. (2016) 95:111-21. doi: 10.1016/j.nbd.2016.07.016

72. Seo K, Seo S, Ki SH, Shin SM. Sestrin2 inhibits hypoxia-inducible factor- $1 \alpha$ accumulation via AMPK-mediated prolyl hydroxylase regulation. Free Radic Biol Med. (2016) 101:511-23. doi: 10.1016/j.freeradbiomed.2016.11.014

73. Seo K, Ki SH, Shin SM. Sestrin2-AMPK activation protects mitochondrial function against glucose deprivation-induced cytotoxicity. Cell Signal. (2015) 27:1533-43. doi: 10.1016/j.cellsig.2015.03.003

74. Wolfson RL, Chantranupong L, Saxton RA, Shen K, Scaria SM, Cantor JR, et al. Sestrin2 is a leucine sensor for the mTORC1 pathway. Science. (2016) 351:43-8. doi: 10.1126/science.aab2674

75. Kimball SR, Gordon BS, Moyer JE, Dennis MD, Jefferson LS. Leucine induced dephosphorylation of Sestrin2 promotes mTORC1 activation. Cell Signal. (2016) 28:896-906. doi: 10.1016/j.cellsig.2016.03.008

76. Zhang XY, Wu XQ, Deng R, Sun T, Feng GK, Zhu XF. Upregulation of sestrin 2 expression via JNK pathway activation contributes to autophagy induction in cancer cells. Cell Signal. (2013) 25:150-8. doi: 10.1016/j.cellsig.2012.09.004

77. Kumar A, Giri S, Shaha C. Sestrin2 facilitates glutamine dependent transcription of PGC-1 $\alpha$ and survival of liver cancer cells under glucose limitation. FEBS J. (2018) 285:1326-45. doi: 10.1111/febs.14406

78. Netea-Maier RT, Plantinga TS, van de Veerdonk FL, Smit JW, Netea MG. Modulation of inflammation by autophagy: consequences for human disease. Autophagy. (2016) 12:245-60. doi: 10.1080/15548627.2015.1071759

79. Shintani T, Klionsky DJ. Autophagy in health and disease: a double-edged sword. Science. (2004) 306:990-5. doi: 10.1126/science.1099993

80. Kim KH, Lee MS. Autophagy: a key player in cellular and body metabolism. Nat Rev Endocrinol. (2014) 10:322-37. doi: 10.1038/nrendo.2014.35

81. Liu X, Niu Y, Yuan H, Huang J, Fu L. AMPK binds to sestrins and mediates the effect of exercise to increase insulin-sensitivity through autophagy. Metabolism. (2015) 64:658-65. doi: 10.1016/j.metabol.2015.01.015

82. Rhee SG, Bae SH. The antioxidant function of sestrins is mediated by promotion of autophagic degradation of Keap1 and Nrf2 activation and by inhibition of mTORC1. Free Radic Biol Med. (2015) 88:205-11. doi: 10.1016/j.freeradbiomed.2015.06.007

83. Maiuri MC, Malik SA, Morselli E, Kepp O, Criollo A, Mouchel PL, et al. Stimulation of autophagy by the p53 target gene Sestrin2. Cell Cycle. (2009) 8:1571-6. doi: $10.4161 /$ cc.8.10.8498 
84. Hou YS, Guan JJ, Xu HD, Wu F, Sheng R, Qin ZH. Sestrin2 protects dopaminergic cells against rotenone toxicity through AMPKdependent autophagy activation. Mol Cell Biol. (2015) 35:2740-51. doi: 10.1128/MCB.00285-15

85. Ro SH, Semple IA, Park H, Park H, Park HW, Kim M, et al. Sestrin2 promotes Unc-51-like kinase 1 mediated phosphorylation of p62/sequestosome-1. FEBS J. (2014) 281:3816-27. doi: 10.1111/febs.12905

86. Bravo R, Parra V, Gatica D, Rodriguez AE, Torrealba N, Paredes F, et al. Endoplasmic reticulum and the unfolded protein response: dynamics and metabolic integration. Int Rev Cell Mol Biol Acad Press. (2013) 301:215-90. doi: 10.1016/B978-0-12-407704-1.00005-1

87. Oakes SA, Papa FR. The role of endoplasmic reticulum stress in human pathology. Ann Rev Pathol. (2015) 10:173-94. doi: 10.1146/annurev-pathol-012513-104649

88. Pluquet O, Pourtier A, Abbadie C. The unfolded protein response and cellular senescence. A review in the theme: cellular mechanisms of endoplasmic reticulum stress signaling in health and disease. Am J Physiol Cell Physiol. (2015) 308:C415-C425. doi: 10.1152/ajpcell.00334.2014

89. Brüning A, Rahmeh M, Friese K. Nelfinavir and bortezomib inhibit mTOR activity via ATF4-mediated sestrin-2 regulation. Mol Oncol. (2013) 7:1012-8. doi: 10.1016/j.molonc.2013.07.010

90. Lamkanfi M, Dixit V. Mechanisms and functions of inflammasomes. Cell. (2014) 157:1013-22. doi: 10.1016/j.cell.2014.04.007

91. He Y, Hara H, Núñez G. Mechanism and regulation of NLRP3 inflammasome activation. Trends Biochem Sci. (2016) 41:1012-21. doi: 10.1016/j.tibs.2016.09.002

92. Wang X, Liu W, Zhuang D, Hong S, Chen J. Sestrin2 and sestrin3 suppress NK-92 cell-mediated cytotoxic activity on ovarian cancer cells through AMPK and mTORC1 signaling. Oncotarget. (2017) 8:90132-43. doi: 10.18632/oncotarget.21487

93. Hu HJ, Shi ZY, Lin XL, Chen SM, Wang QY, Tang SY. Upregulation of sestrin2 expression protects against macrophage apoptosis induced by oxidized low-density lipoprotein. DNA Cell Biol. (2015) 34:296-302. doi: 10.1089/dna.2014.2627

94. Yang K, Xu C, Zhang Y, He S, Li D. Sestrin2 suppresses classically activated macrophages-mediated inflammatory response in myocardial infarction through inhibition of mTORC1 signaling. Front Immunol. (2017) 8:728. doi: 10.3389/fimmu.2017.00728

95. Sundararajan S, Jayachandran I, Balasubramanyam M, Mohan V, Venkatesan B, Manickam N. Sestrin2 regulates monocyte activation through AMPKmTOR nexus under high-glucose and dyslipidemic conditions. J Cell Biochem. (2018) 120:8201-13. doi: 10.1002/jcb.28102

96. Xiao T, Zhang L, Huang Y, Shi Y, Wang J, Ji Q, et al. Sestrin2 increases in aortas and plasma from aortic dissection patients and alleviates angiotensin II-induced smooth muscle cell apoptosis via the Nrf2 pathway. Life Sci. (2019) 218:132-8. doi: 10.1016/j.lfs.2018.12.043

97. Klingemann H, Boissel L, Toneguzzo F. Natural killer cells for immunotherapy-advantages of the NK-92 cell line over blood NK cells. Front Immunol. (2016) 7:91. doi: 10.3389/fimmu.2016.00091

98. Dundar B, Cakmak BD, Boyama BA, Karadag B, Ozgen G. Maternal serum Glycodelin levels in preeclampsia and its relationship with the severity of the disease. J Matern Fetal Neonatal Med. (2017) 31:2884-92. doi: 10.1080/14767058.2017.1359530

99. Ye J, Wang M, Xu Y, Liu J, Jiang H, Wang Z, et al. Sestrins increase in patients with coronary artery disease and associate with the severity of coronary stenosis. Clin Chim Acta. (2017) 472:51-7. doi: 10.1016/j.cca.2017.07.020

100. Shi X, Xu L, Doycheva DM, Tang J, Yan M, Zhang JH. Sestrin2, as a negative feedback regulator of mTOR, provides neuroprotection by activation AMPK phosphorylation in neonatal hypoxic-ischemic encephalopathy in rat pups. J Cereb Blood Flow Metab. (2017) 37:1447-60. doi: 10.1177/0271678X16656201

101. Pappa KI, Lygirou V, Kontostathi G, Zoidakis J, Makridakis M, Vougas $\mathrm{K}$, et al. Proteomic analysis of normal and cancer cervical cell lines reveals deregulation of cytoskeleton-associated proteins. Cancer Genomics Proteomics. (2017) 14:253-66. doi: 10.21873/cgp.20036

102. Chai D, Wang G, Zhou Z, Yang H, Yu Z. Insulin increases sestrin 2 content by reducing its degradation through the $\mathrm{PI} 3 \mathrm{~K} / \mathrm{mTOR}$ signaling pathway. Int J Endocrinol. (2015) 2015:505849. doi: 10.1155/2015/505849
103. Taniguchi CM, Emanuelli B, Kahn CR. Critical nodes in signaling pathways: insights into insulin action. Nat Rev Mol Cell Biol. (2006) 7:85-96. doi: $10.1038 / \mathrm{nrm} 1837$

104. Singer M, Deutschman CS, Seymour CW, Shankar-Hari M, Annane D, Bauer $\mathrm{M}$, et al. The third international consensus definitions for sepsis and septic shock. (Sepsis-3). JAMA. (2016) 315:801-10. doi: 10.1001/jama.2016.0287

105. van der Poll T, van de Veerdonk FL, Scicluna BP, Netea MG. The immunopathology of sepsis and potential therapeutic targets. Nat Rev Immunol. (2017) 17:407-20. doi: 10.1038/nri.2017.36

106. Delano MJ, Ward PA. Sepsis-induced immune dysfunction: can immune therapies reduce mortality? J Clin Investig. (2016) 126:23-31. doi: 10.1172/JCI82224

107. Kim KM, Yang JH, Shin SM, Cho IJ, Ki SH. Sestrin2: a promising therapeutic target for liver diseases. Biol Pharmaceut Bull. (2015) 38:966-70. doi: 10.1248/bpb.b15-00228

108. Pasha M, Eid AH, Eid AA, Gorin Y, Munusamy S. Sestrin2 as a novel biomarker and therapeutic target for various diseases. Oxidat Med Cell Longevity. (2017) 2017:1-10. doi: 10.1155/2017/3296294

109. Szabó C. The pathophysiological role of peroxynitrite in shock, inflammation, and ischemia-reperfusion injury. Shock. (1996) 6:79-88. doi: 10.1097/00024382-199608000-00001

110. Wu MY, Yiang GT, Liao WT, Tsai AP, Cheng YL, Cheng PW, et al. Current mechanistic concepts in ischemia and reperfusion injury. Cell Physiol Biochem. (2018) 46:1650-67. doi: 10.1159/000489241

111. Zhou D, Zhan C, Zhong Q, Li S. Upregulation of Sestrin-2 expression via P53 protects against 1-methyl-4-phenylpyridinium (MPP+) neurotoxicity. J Mol Neurosci. (2013) 51:967-75. doi: 10.1007/s12031-013-0081-x

112. Wang H, Li N, Shao X, Li J, Guo L, Yu X, et al. Increased plasma sestrin2 concentrations in patients with chronic heart failure and predicted the occurrence of major adverse cardiac events: a 36-month follow-up cohort study. Clin Chim Acta. (2019) 495:338-44. doi: 10.1016/j.cca.2019.04.084

113. Dong Z, Lin C, Liu Y, Jin H, Wu H, Li Z, et al. Upregulation of sestrins protect atriums against oxidative damage and fibrosis in human and experimental atrial fibrillation. Sci Rep. (2017) 7:46307. doi: 10.1038/srep46307

114. Bozinovski S, Vlahos R, Anthony D, McQualter J, Anderson G, Irving $\mathrm{L}$, et al. COPD and squamous cell lung cancer: aberrant inflammation and immunity is the common link. Br J Pharmacol. (2016) 173:635-48. doi: 10.1111/bph.13198

115. Jiang Y, Wang X, Hu D. Mitochondrial alterations during oxidative stress in chronic obstructive pulmonary disease. Int J Chronic Obstruct Pulmonary Dis. (2017) 12:1153-62. doi: 10.2147/COPD.S130168

116. Tomasovic A, Kurrle N, Wempe F, De-Zolt S, Scheibe S, Koli K, et al. Ltbp4 regulates Pdgfr $\beta$ expression via TGF $\beta$-dependent modulation of Nrf2 transcription factor function. Matrix Biol. (2017) 59:109-20. doi: 10.1016/j.matbio.2016.09.006

117. Howell JJ, Manning BD. mTOR couples cellular nutrient sensing to organismal metabolic homeostasis. Trends Endocrinol Metab. (2011) 22:94102. doi: 10.1016/j.tem.2010.12.003

118. Kalupahana NS, Moustaid-Moussa N, Claycombe KJ. Immunity as a link between obesity and insulin resistance. Mol Aspects Med. (2012) 33:1-34. doi: 10.1016/j.mam.2011.10.011

119. Diakos CI, Charles KA, McMillan DC, Clarke SJ. Cancer-related inflammation and treatment effectiveness. Lancet Oncol. (2014) 15:E493-E503. doi: 10.1016/S1470-2045(14)70263-3

120. Matheu A, Maraver A, Klatt P, Flores I, Garcia-Cao I, Borras C, et al. Delayed ageing through damage protection by the Arf/p53 pathway. Nature. (2007) 448:375-9. doi: 10.1038/nature05949

Conflict of Interest: The authors declare that the research was conducted in the absence of any commercial or financial relationships that could be construed as a potential conflict of interest.

Copyright (c) 2019 Wang, Zhu and Yao. This is an open-access article distributed under the terms of the Creative Commons Attribution License (CC BY). The use, distribution or reproduction in other forums is permitted, provided the original author(s) and the copyright owner(s) are credited and that the original publication in this journal is cited, in accordance with accepted academic practice. No use, distribution or reproduction is permitted which does not comply with these terms. 